\title{
Sentimentos partidários e atitudes políticas entre os brasileiros
}

\author{
Ednaldo Ribeiro \\ Centro de Ciências Humanas letras e Artes \\ Departamento de Ciências Sociais \\ Universidade Estadual de Maringá \\ Yan Carreirão \\ Centro de Filosofia e Ciências Humanas \\ Universidade Federal de Santa Catarina \\ Julian Borba \\ Departamento de Ciências Políticas \\ Universidade Federal de Santa Catarina
}

\begin{abstract}
Resumo: O trabalho investiga a evolução dos sentimentos partidários dos eleitores brasileiros entre 2002 e 2010 e suas relações com variáveis atitudinais e de comportamento dos eleitores. Inicialmente, é realizada uma análise descritiva geral da evolução dos sentimentos partidários dos eleitores entre 2002 e 2010, utilizando dados dos ESEB (Estudos Eleitorais Brasileiros) 2002, 2006 e 2010. A seguir, os sentimentos partidários positivos em relação ao PT e ao PSDB são tomados como preditores de variáveis atitudinais (identificação ideológica, atitudes em relação a estatismo, igualdade e democracia) e do voto, a partir de análises multivariadas, também com base nos ESEB 2002 a 2010. O trabalho conclui mostrando que há diferenças interessantes entre eleitores que manifestam sentimentos em relação ao PT e ao PSDB, quanto a atitudes relativas a temas políticos relevantes; além disso, mostra, também, que esses sentimentos estão, ainda, fortemente associados ao voto para presidente.
\end{abstract}

Palavras-chave: sentimentos partidários, atitudes políticas, valores políticos, CSES-ESEB2010.

\begin{abstract}
This paper examines how the partisan feelings of Brazilian voters evolved between 2002 and 2010 and how these feelings relate to attitudinal and behavioral variables. First a general descriptive analysis of this evolution is conducted using data from the ESEBs (Brazilian Electoral Studies) of 2002, 2006 and 2010. Then, based on multivariate analyses and again on CSES-ESEB2002 through 2010, the positive partisan feelings about the PT and the PSDB are taken to be predictors of attitudinal variables (ideological identification, attitudes towards statism, equality and democracy) and votes. The paper finally shows that there are interesting differences among voters that express feelings towards the PT and voters having feelings towards the PSDB as regards attitudes towards relevant political issues. Moreover, the paper shows that these feelings are still strongly connected to voting for president.
\end{abstract}

Keywords: partisan feelings, political attitudes, political values, CSES-ESEB2010.

OPINIÃO PÚBLICA, Campinas, vol. 17, n², Novembro, $2011, p .333-368$ 


\section{Introdução ${ }^{1}$}

Uma das discussões centrais no debate sobre partidos políticos é aquela relacionada à identificação dos eleitores com essas organizações. Os níveis de identificação são indicadores fortes de quão institucionalizado é um sistema partidário.

O problema é que há algumas décadas assiste-se, no plano internacional, a um declínio nos níveis de identificação partidária, na diferenciação ideológica entre os partidos, bem como na relevância dos partidos em termos de estruturação da decisão do voto (WATTENBERG, 1991 E 1998; DALTON \& WATTENBERG, 1993 E 2001; CLARKE \& STEWART, 1998).

No caso do Brasil, o diagnóstico predominante na literatura apontava uma fragilidade histórica do sistema partidário (LAMOUNIER E MENEGUELLO, 1986; MAINWARING, 1991 E 2001)². Em consonância com esse diagnóstico, os níveis de identificação, sua relação com o voto e sua coerência em termos de atitudes políticas foram também, predominantemente, considerados baixos (MAINWARING, 2001; CARREIRÃO E KINZO, 2004; KINZO, 2005).

O trabalho de Singer (2000) representou uma mudança nas interpretações dominantes sobre tal fenômeno ao apontar para a importância das identificações ideológicas e partidárias dos eleitores brasileiros na estruturação do voto nas eleições de 1989 e 1994. Com relação ao papel dos sentimentos partidários, tal interpretação foi parcialmente confirmada por estudos como o de Carreirão (2007); por outro lado, estudos questionam tais evidências apontando para a fragilidade da identificação, bem como para a incoerência entre os sentimentos partidários e as opiniões políticas dos eleitores (REIS, 2000; RENNÓ, 2007; PAIVA et al, 2007).

A reeleição do presidente Lula em 2006 motivou uma série de trabalhos que analisaram o papel do programa Bolsa Família no resultado daquela eleição, as mudanças nas bases geográficas e sociais das votações em Lula, em diferentes

\footnotetext{
${ }^{1}$ Este trabalho é fruto de pesquisa apoiada pelo Conselho Nacional de Desenvolvimento Científico e Tecnológico (CNPq), através de Bolsa de Produtividade e de Bolsas de Iniciação Científica.

2 É importante salientar a não existência de um consenso quanto a esse diagnóstico. Para o período pré 1964, ver Lavareda (1991). Para o sistema partidário atual, ver Braga (2010) e Tarouco (2010), que partem de outras noções de institucionalização, diferentes da proposta por Mainwaring e bem menos exigentes em relação aos critérios que caracterizariam um sistema partidário como (mais ou menos) institucionalizado.
} 
RIBEIRO, E.; CARREIRÃO, Y.; BORBA, J. Sentimentos partidários e atitudes políticas...

eleições presidenciais, e ainda, as comparações das votações de Lula e as do PT, nas eleições para a Câmara Federal (NICOLAU e PEIXOTO, 2007; HUNTER e POWER, 2007; ZUCCO, 2008; SOARES E TERRON, 2008; TERRON, 2009; SINGER, 2009 e 2010; TERRON e SOARES, 2010, RENNÓ e CABELLO, 2010) ${ }^{3}$.

Trabalhos como os de Samuels (2004 e 2008), Veiga (2007), Carreirão (2008), Singer (2010) e Venturi (2010) têm investigado as bases sociais dos partidos, enfatizando mais as identificações partidárias do que o voto, bem como as opiniões e atitudes políticas dos eleitores e sua relação com os sentimentos partidários.

Samuels (2004 e 2008) estuda as bases do petismo e suas transformações, principalmente em função da chegada do PT ao poder nacional. O autor encontra poucas mudanças nesse eleitorado identificado com o partido ao comparar os resultados de surveys realizados em 2002 e 2007. Sua ênfase é dada às características atitudinais: "Nos dois anos, encontramos que o petista médio vive em centros urbanos relativamente bem desenvolvidos, participa ativamente da política, está relativamente mais informado do que a maioria dos brasileiros, acredita fortemente que seu voto faz diferença para a política e é contrário ao clientelismo, mas importa-se menos com a corrupção". O trabalho de Singer (2010) também se concentra no caso do PT, em especial na contradição entre duas matrizes ideológicas e programáticas que convivem no partido. ${ }^{4}$ Ao comparar resultados de surveys realizados entre 2002 e 2010 conclui que "a base do PT, que era predominantemente de esquerda, passou a abrigar um contingente análogo de eleitores situados à direita" (p.108). Tanto Singer quanto Venturi (2010) apontam mudanças no perfil socioeconômico dos eleitores com preferência pelo PT: comparativamente ao período inicial do atual sistema partidário, em anos mais recentes diminui, na composição interna desse eleitorado, a importância dos eleitores de mais alta escolaridade, de mais alta renda e da região Sudeste.

Os estudos de Veiga (2007) e Carreirão (2008) incluem outros partidos em suas análises. Veiga compara dados da coleção ESEB (Estudo Eleitoral Brasileiro) para 2002 e 2006 e aponta para mudanças nas bases de identificação partidária, em especial no PT, que se deslocou para um eleitorado de menor renda e menor

\footnotetext{
${ }^{3}$ Boas revisões dessa literatura são feitas em Terron e Soares (2010) e Rennó e Cabello (2010).

4 O autor as denomina de "espírito do Sion", que faz referência à fundação do PT e sua afirmação como um partido socialista e o "espírito do Anhembi", referindo-se ao programa de governo de Lula nas eleições de 2002 e à "Carta ao povo brasileiro", onde o candidato afirma seu compromisso com capital estrangeiro, a responsabilidade fiscal, a estabilidade das contas públicas etc.
} 
escolaridade. Segundo Veiga, essa mudança de base social poderia ser uma das razões que explicaria o deslocamento ao centro e à direita daqueles que se identificam com o partido. Já o PMDB teria ampliado sua base entre os eleitores de maior escolaridade e da região Sul, deslocando-se para a esquerda na autolocalização ideológica. Por fim, PSDB e PFL (atual DEM) teriam experimentado mudanças menores em termos de bases sociais. Carreirão (2008) toma como base empírica quatro surveys realizados em 1990, 1997, 2002 e 2007, com a hipótese de que as opiniões políticas dos eleitores que manifestam sentimentos por diferentes partidos eram mais diferenciadas entre si em 1990 do que em 2007. A variável que teria exercido efeito central nessa diluição das diferenças ideológicas e políticas entre o eleitorado seria a chegada do PT e de Lula à Presidência da República. Entre os elementos que confirmariam sua hipótese está o fato de que os "eleitores petistas" e os "eleitores peessedebistas" vão se tornando progressivamente indiferenciados do conjunto do eleitorado quanto ao posicionamento ideológico. Do mesmo modo, no plano das opiniões políticas dos eleitores, "em 1990, havia maior preferência por partidos à esquerda entre eleitores mais democráticos, igualitários, participativos ou liberais, em questões morais; já em 2007, as opiniões dos eleitores têm muito pouca associação com o partido que preferem ou rejeitam (...)" (CARREIRÃO, 2008, p.339).

O conjunto de trabalhos apresentados acima aponta para mudanças significativas nos últimos anos, nas bases sociais, ideológicas e atitudinais dos partidos políticos brasileiros, causadas em especial pela chegada do PT . justamente aquele que teria sido a "espinha dorsal do sistema partidário brasileiro" (Singer, 2000) pós-redemocratização - ao poder. O presente trabalho busca verificar em que medida tais tendências se mantêm ou se alteram, considerando o cenário das eleições de 2010 e tomando como base empírica os dados pós-eleitorais do ESEB 2010. Nosso foco está direcionado para os "sentimentos partidários" do eleitorado (partido que representa a maneira de o eleitor pensar, partido de que o eleitor gosta, partido que rejeita) entre 2002 e 2010 e suas relações com variáveis atitudinais e de comportamento.

Inicialmente realizamos uma breve apresentação da literatura sobre identificação partidária. Em seguida, fazemos uma análise descritiva mais geral da evolução dos sentimentos partidários dos eleitores brasileiros entre 2002 e 2010, utilizando dados dos ESEBs 2002, 2006 e 2010. Por fim, realizamos uma análise segundo a qual os sentimentos partidários positivos (partido que representa a maneira de o eleitor pensar, partido de que o eleitor gosta) em relação ao PT e ao 
RIBEIRO, E.; CARREIRÃO, Y.; BORBA, J. Sentimentos partidários e atitudes políticas...

PSDB são considerados proxys de um posicionamento "petista" ou "tucano", tomado como preditor de variáveis atitudinais (identificação ideológica, atitudes em relação a estatismo, igualdade e democracia, aceitação da repressão e da censura) e do voto, a partir de análises multivariadas, com base no ESEB 2010 ou, quando possível, nos ESEBs 2002 a $2010^{5}$.

Foram estudadas também as manifestações de rejeição ("partido em que não votaria de jeito nenhum") a esses dois partidos. Os resultados, em geral corroboram as conclusões tiradas com base nos sentimentos partidários positivos, quase como uma imagem invertida: as tendências de associações entre uma variável atitudinal e sentimentos positivos em relação ao PT, são, via de regra, semelhantes às que ocorrem entre essa mesma variável atitudinal e a rejeição ao PSDB. Por isso, não descreveremos as análises com base na rejeição partidária. Uma forma de operacionalizar os sentimentos partidários (positivos e negativos) simultaneamente em relação ao PT e ao PSDB também foi criada, seguindo estudo anterior de Carreirão (2008). A partir dessa forma de operacionalização, apresentamos as análises cujos resultados também corroboram as conclusões mais gerais obtidas a partir da análise apenas dos sentimentos positivos em relação àqueles partidos.

\section{Interpretações sobre identificação partidária}

O tema da identificação entre eleitores e partidos políticos tem uma longa história na Ciência Política. Entre as principais perspectivas de análise destacam-se a Escola de Michigan e a teoria da escolha racional ${ }^{6}$. Na visão dos autores filiados à Escola de Michigan, a identificação partidária (IP) se originaria de uma adesão de base psicológica aos partidos constatada por meio de dados de surveys sobre comportamento eleitoral. Tratar-se-ia de uma identidade forjada em bases afetivas no processo de socialização. Como salienta Figueiredo, a tese é a de que, "uma vez formada, a identificação partidária tende a tornar-se estável, ou seja, os eleitores que têm identificação partidária em graus variados, inclinam-se a 'ver' a política e orientar suas ações numa direção partidária" (FIGUEIREDO, 1991, p. 37).

\footnotetext{
${ }^{5}$ Embora assumamos aqui que associações entre sentimentos partidários e atitudes dos eleitores podem ser indícios de que aqueles tendem a estruturar essas, é preciso tomar com cautela a relação de causalidade pressuposta, já que ela pode ser no sentido inverso ao aqui assumido: primeiro as pessoas "formariam" essas atitudes e depois identificar-se-iam com os partidos. Como dados de survey não nos permitem testar o que vem primeiro, a ressalva é necessária.

${ }^{6}$ Sobre essas teorias, ver Figueiredo (1991) e Castro (1992).
} 
A teoria da escolha racional dá um outro significado à identificação partidária e a seu impacto sobre a decisão do voto. Para Downs (1957), a identificação partidária explica-se porque os partidos (e as ideologias políticas) são referenciais que os eleitores usam para diminuir custos de obtenção e processamento das informações políticas necessárias para sua tomada de decisão. Observando em algumas ocasiões que um partido se comporta em conformidade com seus interesses (ou defendendo certas idéias mais do que outras), o eleitor pode, em uma próxima eleição, utilizar esse conhecimento prévio para decidir seu voto, economizando recursos, especialmente o tempo, para se informar e fazer sua escolha. Não se trata, portanto, de uma identificação afetiva ou normativamente fundada, como preconiza a Escola de Michigan. Para Fiorina (1981), se a socialização do indivíduo previamente à sua vida adulta tem um peso na identificação partidária, peso ainda maior tem a avaliação que o indivíduo faz da experiência acumulada como eleitor ao longo de sua vida adulta. Nesse sentido, os cidadãos, para esse autor, monitoram as promessas e desempenhos partidários ao longo do tempo, encapsulando essas observações em um julgamento sumário chamado identificação partidária. A IP seria, portanto, uma informação sintética e econômica que é utilizada pelo eleitor para lidar com futuros incertos, e pode mudar ao longo do tempo, caso a avaliação do eleitor sobre os partidos mude.

De certa forma, nosso problema de pesquisa (que inclui a tentativa de verificar se os sentimentos partidários ${ }^{7}$ têm influência nas atitudes dos eleitores), ainda que apenas hipoteticamente, parte de uma concepção de IP próxima à da Escola de Michigan já que, nessa perspectiva, espera-se que, após formada a IP, os eleitores "vejam a política sob a ótica do partido com que se identificam". A relação de causalidade ali pressuposta é a de que as IPs influenciam opiniões e atitudes dos eleitores. Uma limitação metodológica de nosso estudo, derivada do fato de que trabalhamos com surveys, é a de que não podemos estabelecer relações de causalidade a partir das associações encontradas. De toda forma, resolvemos sondar se seria plausível postular uma relação de causalidade desse tipo, a partir especialmente das análises multivariadas, tomando como variáveis dependentes certas atitudes dos eleitores, e como uma das variáveis independentes, seus sentimentos partidários.

\footnotetext{
${ }^{7}$ Como consideramos além das preferências as rejeições, não trabalhamos aqui com a noção de IP e sim de "sentimentos partidários".
} 
RIBEIRO, E.; CARREIRÃO, Y.; BORBA, J. Sentimentos partidários e atitudes políticas...

\section{Sentimentos partidários}

Esta seção descreve a distribuição dos eleitores segundo os sentimentos partidários manifestos nas três pesquisas analisadas, ESEB 2002, 2006 e 2010. Consideramos aqui como manifestações de sentimentos positivos em relação aos partidos as repostas às questões "Existe algum partido que representa a forma como o(a) Sr.(a) pensa?" (espontânea e única) e "Existe algum partido que o(a) Sr.(a) goste?" (espontânea e múltipla, podendo o eleitor mencionar até três opções) ${ }^{8}$. Como manifestação negativa, consideramos as respostas à questão sobre rejeição partidária "Em quais desses partidos o(a) $\operatorname{sr}(a)$. não votaria de jeito nenhum?", (estimulada e múltipla). Inicialmente apresentamos os dados relativos a cada uma das manifestações para os principais partidos; em seguida agregamos os dados referentes aos sentimentos positivos (partido que representa a maneira de pensar do eleitor e/ou partido de que o eleitor gosta), mas apenas para o PT e para - PSDB, que são os principais focos de nossa análise. Por fim, criamos uma variável que sintetiza o conjunto de sentimentos positivos e negativos em relação ao PT e ao PSDB, simultaneamente.

A Tabela 1 apresenta os percentuais de eleitores que indicaram algum partido, em resposta à questão: "Existe algum partido que representa a forma como o(a) Sr.(a) pensa?"9. O percentual declina de 35,5\% em 2002 para 27,4\% em 2006, subindo para 38,7\% em 2010. A Tabela também apresenta estes mesmos dados, desagregados por partido (incluindo apenas aqueles com mais de $1 \%$ de menções). Vemos que as principais variações, que explicam em grande medida as variações globais foram a queda nas menções ao PT entre 2002 e 2006 - resultado devido essencialmente ao desgaste do partido por conta do escândalo do "mensalão" - e a recuperação do partido entre 2006 e 2010. Outras mudanças incluem o declínio do PFL (DEM), um pequeno crescimento do PSDB na última pesquisa e as menções ao PV em 2010, fruto basicamente do "fenômeno Marina" naquela eleição.

\footnotetext{
${ }^{8}$ Resolvemos considerar apenas a $1^{\text {a }}$ menção (espontânea) feita pelos entrevistados, por julgar que ela deve refletir a preferência (ou "gosto") mais intensa (o), que poderia ter maior associação com atitudes e comportamentos dos eleitores. Além disso, a forma como operacionalizamos a variável "sentimentos partidários" (positivos) já agrega também os eleitores que afirmam ter um partido que representa a forma como eles pensam.

${ }^{9}$ Nessa questão o percentual de respostas "sim" foi um pouco maior, mas os percentuais no gráfico correspondem aos eleitores que, após terem respondido "sim" a essa questão, na pergunta a seguir ("qual partido?") indicaram algum partido. Excluímos, em relação a esta última pergunta, as respostas "não sabe" ou "não respondeu", bem como os eleitores que indicaram partidos inexistentes ou nomes de políticos ("partido do Lula", p/ex).
} 
Tabela 1

Partidos que melhor representam a maneira como o eleitor pensa e partidos que o eleitor gosta (2002-2010) (\%)

\begin{tabular}{|l|l|l|l|l|l|l|l|l|l|l|l|l|}
\hline \multirow{2}{*}{ Ano } & \multicolumn{2}{|l|}{ DEM (PFL) } & \multicolumn{2}{l|}{ PMDB } & \multicolumn{2}{l|}{ PT } & \multicolumn{2}{l|}{ PSDB } & \multicolumn{2}{l|}{ PV } & \multicolumn{2}{l|}{ TOTAL } \\
\cline { 2 - 14 } & $\begin{array}{l}\text { Pensa } \\
*\end{array}$ & $\begin{array}{l}\text { Gosta } \\
* *\end{array}$ & Pensa & Gosta & Pensa & Gosta & Pensa & Gosta & Pensa & Gosta & Pensa & Gosta \\
\hline $\mathbf{2 0 0 2}$ & 2,2 & 3,4 & 3,8 & 7,2 & 23,1 & 25,6 & 3,7 & 4,5 & - &. & 35,5 & 48,8 \\
\hline $\mathbf{2 0 0 6}$ & - & - & 3,7 & 3,4 & 17,6 & 21,6 & 3,6 & 4,5 & - & - & 27,4 & 33,1 \\
\hline $\mathbf{2 0 1 0}$ & - & - & 2,7 & 5,2 & 24,5 & 27,7 & 5,7 & 7,8 & 3,7 & 3,5 & 38,7 & 47,7 \\
\hline
\end{tabular}

Fonte: ESEB 2002, 2006 e 2010.

*Pensa: "Existe algum partido que representa a forma como o(a) Sr.(a) pensa?"

**Gosta: "Existe algum partido que o(a) Sr.(a) goste?"

Obs. Os valores da coluna total não são iguais à soma dos percentuais por partido, porque há outros partidos mencionados pelos eleitores que não aprecem na tabela.

Ainda na Tabela 1 temos as respostas positivas à questão "Existe algum partido que o(a) Sr.(a) goste?" (resultados globais e desagregados por partido, incluindo apenas os que tiveram mais de $1 \%$ de menções). Há certo grau de superposição com os dados apresentados, mas a tendência mais geral é de que haja, em cada pesquisa, uma porcentagem a mais de eleitores que gostam de determinado partido, comparativamente aos eleitores que indicam que esse partido representa sua maneira de pensar. Em termos da evolução temporal, os dados seguem as mesmas tendências apresentadas para as respostas à questão "Existe algum partido que representa a forma como o (a) Sr. (a) pensa?"

Nas análises feitas mais à frente, foram incluídos como eleitores que manifestaram sentimentos positivos em relação ao PT tanto os eleitores que expressaram que esse partido representa sua maneira de pensar, quanto os que disseram que gostam dele. O mesmo foi feito em relação ao PSDB. Levando em consideração as duas variáveis anteriores, foi construído um índice somatório para PT e outro para PSDB. Em ambos os casos o 0 (zero) representa pessoas que não identificam o partido em questão como representante da maneira como pensam e 
RIBEIRO, E.; CARREIRÃO, Y.; BORBA, J. Sentimentos partidários e atitudes políticas...

que também responderam que não gostam dos partidos. 01 equivale a uma resposta positiva e o 2 , duas respostas positivas.

A Tabela 2 apresenta esses dados. Ao considerarmos os que responderam positivamente pelo menos em uma das variáveis, construímos duas variáveis de sentimentos partidários dicotômicas. Em 2010, no caso do PT temos $32.2 \%$ que se "identificam" por acreditar que o partido representa sua forma de pensar ou simplesmente por gostar; no PSDB o percentual é de $9.3 \%$.

Tabela 2

Sentimentos partidários (índice somatório) - PT e PSDB (2002-2010) (\%)

\begin{tabular}{|c|c|c|c|c|c|c|}
\hline \multirow{2}{*}{$\begin{array}{c}\text { Sentimento } \\
\text { Partidário }\end{array}$} & \multicolumn{2}{|c|}{2002} & \multicolumn{2}{c|}{2006} & \multicolumn{2}{c|}{2010} \\
\cline { 2 - 7 } & PT & PSDB & PT & PSDB & PT & PSDB \\
\hline 0 & 68,7 & 94,3 & 75,9 & 94,8 & 67.9 & 90.8 \\
\hline 1 & 14,0 & 3,3 & 9,1 & 2,4 & 12.2 & 5.1 \\
\hline 2 & 17,3 & 2,5 & 15,1 & 2,8 & 20.0 & 4.2 \\
\hline Total (N) & $(2513)$ & $(2513)$ & $(1000)$ & $(1000)$ & $(2000)$ & $(2000)$ \\
\hline
\end{tabular}

Fonte: ESEB 2002, 2006 e 2010.

Nota: os percentuais foram calculados sobre o total de entrevistados.

Como nossa intenção é verificar o impacto desses sentimentos positivos em relação ao PT e ao PSDB sobre aquelas dimensões dos valores políticos (estatismo, democratismo, igualitarismo), realizamos primeiramente testes de associação entre sentimentos e valores, e em seguida construímos modelos multivariados com essas diferentes medidas (índices somatórios ou medidas dicotômicas).

Outra forma de operacionalização da variável relativa aos sentimentos partidários em relação a PT e PSDB foi a construção, na forma de uma escala, incluindo a rejeição e considerando, simultaneamente, as diferentes manifestações em relação a esses partidos ${ }^{10}$. Essa escala vai de um extremo que inclui eleitores que manifestam sentimento positivo pelo PT e simultaneamente rejeição ao PSDB, ao extremo oposto, que inclui eleitores que manifestam sentimento positivo pelo PSDB e, simultaneamente, rejeição ao PT. A Tabela 3 apresenta a distribuição dos eleitores segundo essa escala, nas três pesquisas sob análise.

\footnotetext{
10 A Tabela Anexa 1 mostra a forte associação entre o voto e os sentimentos partidários medidos através dessa escala, o que nos parece justificar o uso dessa medida operacional dos sentimentos partidários.
} 
Um primeiro dado relevante é que o percentual de eleitores que foram classificados em situação de neutralidade, variou entre 39\% e 45\%. Isso não significa que o percentual de eleitores que manifestaram algum sentimento em relação a algum dos (ou aos) dois partidos variou entre 55\% e 61\% (valores complementares). Na realidade, os que não manifestaram nenhum sentimento em relação a nenhum dos dois partidos variaram de 32 a 35\% nas três pesquisas. Portanto, cerca de dois terços dos eleitores manifestam algum tipo de sentimento em relação aos dois partidos brasileiros mais importantes. Ocorre que há várias situações, classificadas como "situações neutras", em que há manifestações positivas e negativas simultaneamente em relação a um mesmo partido (poucos casos) e situações em que há rejeição simultânea aos dois partidos (entre 3\% e $8,7 \%$ dos casos nas pesquisas).

Tabela 3

Sentimentos em relação ao PT e ao PSDB (escala) (2002, 2006 e 2010) (\%)

\begin{tabular}{|c|c|c|c|c|c|c|c|}
\hline \multirow{2}{*}{ ESEB } & \multicolumn{7}{|c|}{ Sentimentos em relação ao PT e PSDB } \\
\cline { 2 - 8 } & $\begin{array}{c}\text { Positivo } \\
\text { PT e } \\
\text { Rejeição } \\
\text { PSDB }\end{array}$ & $\begin{array}{c}\text { Positivo } \\
\text { PT }\end{array}$ & $\begin{array}{c}\text { Rejeição } \\
\text { PSDB }\end{array}$ & $\begin{array}{c}\text { Situações } \\
\text { neutras }\end{array}$ & $\begin{array}{c}\text { Rejeição } \\
\text { PT }\end{array}$ & $\begin{array}{c}\text { Positivo } \\
\text { PSDB }\end{array}$ & $\begin{array}{c}\text { Positivo } \\
\text { PSDB e } \\
\text { Rejeição } \\
\text { PT }\end{array}$ \\
\hline 2002 & 15 & 16 & 13 & 39 & 13 & 2 & 3 \\
\hline 2006 & 12 & 11 & 13 & 45 & 14 & 1 & 3 \\
\hline 2010 & 16 & 15 & 11 & 39 & 11 & 3 & 5 \\
\hline
\end{tabular}

Fonte: ESEB 2002, 2006 e 2010. (Valores arredondados).

Nota: foram consideradas "situações neutras" aquelas em que o eleitor não manifestou nenhum sentimento em relação aos dois partidos, ou manifestou o mesmo sentimento (positivo ou negativo) em relação aos dois, ou manifestou sentimentos contraditórios (positivos e negativos, simultaneamente) a um mesmo partido.

A leitura dos dados da tabela, portanto, subestima o grau de rejeição aos dois partidos. Em relação ao PT os percentuais totais foram de 21,8\% em 2002, 26,7\% em 2006 e 19,8\% em 2010. Como se vê, não só houve um declínio dos sentimentos positivos em relação ao partido em 2006 (como já observado mais acima), como aumentou a rejeição naquele ano. Da mesma forma, a rejeição diminui bastante entre 2006 e 2010. Em relação ao PSDB os percentuais de 
RIBEIRO, E.; CARREIRÃO, Y.; BORBA, J. Sentimentos partidários e atitudes políticas...

rejeição foram de 33,8\% em 2002, 34,3\% em 2006 e 30\% em 2010. Ou seja, a rejeição ao PSDB foi sempre maior do que em relação ao PT, inclusive em $2006^{11}$.

Nas seções seguintes estão analisadas as associações entre os sentimentos partidários dos eleitores e variáveis atitudinais (atitudes em relação a democracia, estatismo, igualdade, censura aos meios de comunicação e repressão a manifestações e passeatas) e comportamental (voto). A análise privilegia os dados do ESEB 2010, já que foi o estudo dessa base que motivou este trabalho. No caso das atitudes em relação à democracia foi possível fazer os mesmos tipos de análises também para os dados do ESEB2002 e do ESEB2006, já que as perguntas utilizadas para operacionalizar as medidas dessas atitudes eram semelhantes nos três questionários. Para as demais atitudes isso não foi possível, porque as perguntas que permitiram a construção de nossas medidas para 2010 não existiam nos questionários anteriores.

Para cada medida atitudinal apresentamos inicialmente suas associações/correlações com os sentimentos partidários; em seguida, desenvolvemos análises multivariadas (regressão múltipla ou regressão logística), de forma a testar se, ao incluirmos outras variáveis na análise, os resultados das associações encontradas na análise bivariada são (ou não) corroborados, de forma a evitar possíveis conclusões espúrias.

\section{Sentimentos partidários e atitudes em relação à democracia}

Esta seção apresenta, inicialmente, as associações entre os sentimentos partidários dos eleitores e suas atitudes em relação à democracia. Em seguida, são dispostos os resultados de modelos de regressão que tomam as atitudes relativas à democracia como variável dependente e incluem, entre outras variáveis explicativas, os sentimentos partidários, de forma a verificar se os resultados encontrados na análise de associação se mantêm quando se incluem outras variáveis na explicação das atitudes em relação à democracia.

No que concerne às atitudes em relação à democracia, optamos por utilizar duas questões do questionário ESEB 2010 - questões já clássicas em pesquisas sobre valores políticos - para duas diferentes medidas de atitudes frente à

\footnotetext{
11 Pesquisas do Datafolha mostram que o PT recuperou-se, no que respeita à preferência partidária, entre o segundo semestre de 2005 (auge do "mensalão") e o final de 2006, quando foi aplicado o ESEB. Provavelmente o mesmo ocorreu com a rejeição ao partido.
} 
democracia ${ }^{12}$. A Tabela 4 apresenta as associações entre essas medidas e os sentimentos partidários dos eleitores. Quando consideramos os sentimentos por um dos partidos, individualmente, vemos que, tanto a preferência, quanto a adesão à democracia são associadas positivamente à "preferência" pelo $\mathrm{PT}^{13}$, nas três pesquisas.

\section{Tabela 4}

\section{Associações (Gamma) entre sentimentos partidários e preferência/adesão democrática $(2002 ; 2006 ; 2010)$}

\begin{tabular}{|l|c|c|c|c|c|c|c|c|c|}
\hline \multirow{2}{*}{ Atitudes } & \multicolumn{3}{|c|}{ Sentim. Positivo PT } & \multicolumn{3}{c|}{$\begin{array}{c}\text { Sentim. Positivo } \\
\text { PSDB }\end{array}$} & \multicolumn{3}{c|}{$\begin{array}{c}\text { Sentimentos } \\
\text { PT/PSDB }\end{array}$} \\
\cline { 2 - 9 } & 2002 & 2006 & 2010 & 2002 & 2006 & 2010 & 2002 & 2006 & 2010 \\
\hline $\begin{array}{l}\text { Preferência } \\
\text { pela } \\
\text { democracia }\end{array}$ & $0,11^{*}$ & $0,30^{*}$ & $0,18^{*}$ & $0,26^{*}$ & $-0,08$ & $-0,15$ & $\cdot$ & $\cdot$ & $\cdot$ \\
\hline $\begin{array}{l}\text { Adesão à } \\
\text { democracia }\end{array}$ & $0,22^{*}$ & $0,47^{*}$ & $0,27^{*}$ & $0,30^{*}$ & $0,53^{*}$ & $-0,16$ & $\cdot$ & $\cdot$ & - \\
0,05 & $0,35^{*}$ & $0,14^{*}$ \\
\hline
\end{tabular}

Fonte: ESEB 2002, 2006 e 2010.

Nota: ${ }^{*}$ sig< $<0,05$.

As associações com os sentimentos partidários são menores para preferência pela democracia, comparativamente à adesão à democracia. Os valores mais altos são encontrados em 2006. No que respeita ao PSDB, somente em 2002

\footnotetext{
12 Denominamos a primeira de "preferência pela democracia", construída a partir da questão: "Na sua opinião: 1 - A democracia é sempre melhor que qualquer outra forma de governo; ou 2 - Em algumas situações é melhor uma ditadura do que uma democracia; 3 . Tanto faz / nenhuma das duas é melhor (espontânea)". Operacionalizamos a medida como uma variável dicotômica, juntando as respostas 2 e 3 (que assumem o valor zero na nova variável). A segunda medida, que chamamos de "adesão à democracia" foi baseada na questão: "A democracia tem alguns problemas, mas é melhor do que qualquer outra forma de governo. O(a) Sr.(a) concorda ou discorda dessa afirmação? Muito ou pouco? 1) Concorda muito; 2) Concorda um pouco; 3) Nem concorda nem discorda; 4) Discorda um pouco; 5) Discorda muito". Recodificamos a variável como dicotômica, juntando os valores 3 (nem concorda, nem discorda), 4 (discorda um pouco) e 5 (discorda muito) no novo valor 0 e juntando 1 (concorda um pouco) e 2 (concorda muito) no novo valor 1". Por serem apenas duas questões, optamos por não juntá. las para construir um índice.

${ }^{13}$ De forma a tornar o texto mais corrente, às vezes utilizamos a expressão "preferência" por um partido para nos referirmos a manifestações, por parte dos eleitores, de sentimentos positivos em relação a esse partido.
} 
RIBEIRO, E.; CARREIRÃO, Y.; BORBA, J. Sentimentos partidários e atitudes políticas...

a preferência pela democracia esteve associada de forma estatisticamente significativa à preferência pelo partido, enquanto a adesão à democracia esteve associada à preferência pelo PSDB em 2002 e 2006. Nestes casos, a associação foi maior do que a encontrada para o PT. Em 2010, as associações são negativas e não significativas estatisticamente. Quando utilizamos a escala de sentimentos em relação ao PT e ao PSDB simultaneamente, os resultados são os seguintes: em 2002, as associações foram não significativas; as associações foram estatisticamente significativas em 2006 e em 2010 (menores neste último ano). 0 sinal negativo indica que a preferência e a adesão à democracia decrescem ao caminharmos da posição extrema da escala onde estão os eleitores que simultaneamente preferem o PT e rejeitam o PSDB para a posição oposta (eleitores que simultaneamente preferem o PSDB e rejeitam o PT).

Assim, com poucas exceções, encontramos, mesmo que com magnitudes e sentidos variados, associações estatisticamente significativas entre sentimentos partidários e atitudes em relação à democracia. De forma a verificar se essas associações se mantêm ao introduzirmos outras medidas, apresentamos alguns modelos de análise de regressão em que as atitudes em relação à democracia são tomadas como variáveis dependentes e os sentimentos partidários, junto com outras medidas, são considerados preditores. Foram desenvolvidos dois tipos de modelos: no Modelo 1, utilizamos separadamente os sentimentos positivos em relação ao PT e ao PSDB (variáveis dicotômicas); no Modelo 2, utilizamos a variável em forma de escala, envolvendo preferências e rejeições por PT e PSDB simultaneamente. Incluímos nesses modelos, além dos sentimentos partidários, algumas variáveis sociodemográficas de controle (sexo, idade, renda e escolaridade) e o posicionamento ideológico dos eleitores ${ }^{14}$. Esta última variável foi incluída de forma a verificar se, com sua introdução, os sentimentos partidários ainda manteriam algum grau de "explicação" das atitudes dos eleitores ${ }^{15}$.

A Tabela 5 apresenta os dados dos modelos (usando regressão logística) relativos à preferência pela democracia ${ }^{16}$. Embora os pseudo- $\mathrm{R}^{2}$ indiquem que os modelos têm um baixo grau de explicação, em vários casos as associações que

14 Sexo como variável dicotômica; as demais operacionalizadas como ordinais (faixas de idade, escolaridade e renda; escala esquerda-direita de 0 a 10).

15 Testamos as associações entre posicionamento ideológico (recodificando a escala de 0 a 10 para três posições) e sentimentos partidários (na versão que inclui simultaneamente PT e PSDB), para ver se as duas variáveis são muito relacionadas. Os resultados estão na Tabela Anexa 2.

${ }^{16}$ Nesse caso, usamos regressão logística porque a variável dependente (preferência pela democracia) foi operacionalizada como dicotômica. O mesmo tipo de análise será usado para outras variáveis dependentes dicotômicas. 
haviam sido encontradas nas análises bivariadas são corroboradas pelos modelos multivariados: no Modelo 1, no caso do PT, em relação a 2006; no caso do PSDB, em relação a 2002, além de aparecer aqui em 2010 uma associação estatisticamente significativa que não aparecia na análise bivariada ${ }^{17}$. Em compensação, em 2002 e 2010 a análise bivariada apontava associação estatisticamente significativa entre preferência pelo PT e preferência pela democracia, enquanto que, na análise multivariada, as associações já não são estatisticamente significativas.

Tabela 5

Modelos logísticos para Preferência pela Democracia (2002; 2006; 2010)

\begin{tabular}{|l|c|c|c|c|c|c|}
\hline \multirow{2}{*}{ Variável } & \multicolumn{3}{c|}{ Modelo 1 } & \multicolumn{4}{c|}{ Modelo 2 } \\
\cline { 2 - 7 } & \multicolumn{3}{|c|}{ Exp(B) } & \multicolumn{3}{c|}{ Exp } \\
\hline Sexo & 2002 & 2006 & 2010 & 2002 & 2006 & 2010 \\
\hline Faixa de Idade &, 976 & 1,504 &, 902 &, 974 & $1,924^{*}$ &, 906 \\
\hline Escolaridade & $1,165^{*}$ & 1,171 & 1,110 & $1,164^{*}$ & 1,262 & 1,113 \\
\hline Faixa de renda familiar & $1,142^{*}$ & 1,128 & 1,094 & $1,034^{*}$ & 1,153 & 1,097 \\
\hline Autoposicionamento & 1,000 &, 935 & 1,140 & 1,000 & 1,022 & 1,140 \\
\hline Sentimentos Positivos & 1,000 & 1,003 & 1,032 &, 999 &, 964 & 1,032 \\
\hline Sentimentos Positivos & 1,191 & $2,263^{*}$ & 1,340 & & & \\
\hline Sentimentos PT/PSDB & $1,861^{*}$ &, 974 &, $574^{*}$ & & & \\
\hline Nagelkerke R & & & & 1,009 &, $700^{*}$ &, $841^{*}$ \\
\hline
\end{tabular}

Fonte: ESEB 2002, 2006 e 2010.

Nota: ${ }^{*}$ sig $<0,05$.

Quanto ao Modelo 2, os dados corroboram o que foi encontrado na análise bivariada: enquanto em 2002 o coeficiente relativo aos sentimentos partidários é estatisticamente não-significativo, em 2006 e em 2010, a associação (negativa)

17 É interessante notar que enquanto em 2002 eleitores que manifestavam preferência pelo partido tinham $86 \%$ a mais de chances de manifestar preferência pela democracia, comparativamente a eleitores que não manifestavam essa preferência. Em 2010 isso se inverte: eleitores que manifestavam preferência pelo PSDB tinham menos chance de preferir a democracia, quando comparados a eleitores sem preferência pelo partido. 
RIBEIRO, E.; CARREIRÃO, Y.; BORBA, J. Sentimentos partidários e atitudes políticas...

encontrada na análise bivariada (Tabela 4) é corroborada na análise multivariada (com um Exp.B menor do que 1, na Tabela 5). Além dos sentimentos partidários, em 2002 outras variáveis apresentaram associação estatisticamente significativa com a preferência pela democracia: à medida que crescia a idade e a escolaridade dos eleitores, aumentava sua preferência pela democracia, nos dois modelos. No modelo 2 a variável sexo se mostrou significativa em 2006: a chance de uma mulher manifestar preferência pela democracia era quase o dobro da dos homens.

A Tabela 6 apresenta os modelos (regressão logística) para adesão à democracia. Também aqui os pseudo $R^{2}$ indicam que os modelos têm um baixo poder explicativo. No Modelo 1 , as associações encontradas na análise bivariada entre preferência pelo PT e adesão à democracia, nas três pesquisas, são corroboradas pela análise multivariada, ou seja, a chance de um eleitor com preferência pelo PT manifestar adesão à democracia é cerca do dobro da de um eleitor sem preferência por esse partido, em 2006 e 2010. Em relação ao PSDB, porém, os resultados encontrados nessa última análise, de certa forma invertem aqueles encontrados nos testes bivariados: nesses havia associação positiva moderada em 2002 e forte em 2006 (ambas estatisticamente significativas), enquanto em 2010 havia associação negativa e fraca, porém estatisticamente não. significativa. $\mathrm{Na}$ análise multivariada, o sentido das associações é o mesmo das análises bivariadas, mas só em 2010 a associação é estatisticamente significativa. 
OPINIÃO PÚBLICA, Campinas, vol. 17, nº 2, Novembro, 2011, p.333-368

Tabela 6

Modelos logísticos para Adesão à Democracia (2002-2006-2010)

\begin{tabular}{|l|c|c|c|c|c|c|}
\hline \multirow{2}{*}{ Variável } & \multicolumn{3}{c|}{ Modelo 1 } & \multicolumn{3}{c|}{ Modelo 2 } \\
\cline { 2 - 8 } & \multicolumn{3}{|c|}{$\operatorname{Exp(B)}(\mathrm{B})$} \\
\hline & 2002 & 2006 & 2010 & 2002 & 2006 & 2010 \\
\hline Sexo & 1,052 & 1,305 & 1,339 & 1,063 & 1,511 & 1,341 \\
\hline Faixa de Idade & 1,004 & 1,028 & 1,135 &, 992 & 1,149 & 1,138 \\
\hline Escolaridade & 1,064 & 1,117 & 1,069 & 1,014 & $1,447^{*}$ & 1,072 \\
\hline Faixa de renda familiar & 1,000 &, $878^{*}$ &, 993 & 1,000 &, 937 &, 989 \\
\hline Auto posicionamento & 1,000 & 1,006 & 1,025 & 1,000 & 1,004 & 1,027 \\
\hline Sentimentos Positivos pelo & $1,477^{*}$ & $2,006^{*}$ & $1,962^{*}$ & & & \\
\hline Sentimentos Positivos pelo & 1,710 & 3,165 &, $573^{*}$ & & & \\
\hline Sentimentos PT/PSDB & & & &, 965 &, $671^{*}$ &, $799^{*}$ \\
\hline Nagelkerke R &, 016 &, 068 &, 036 &, 008 &, 109 &, 035 \\
\hline
\end{tabular}

Fonte: ESEB 2002, 2006 e 2010.

Nota: * sig<0,05.

No que respeita ao Modelo 2, a análise corrobora os achados da análise bivariada: enquanto em 2002 a variável sentimentos partidários foi não significativa, em 2006 e 2010 foi e no sentido já indicado por aquela análise (lá associação negativa; aqui um Exp.B menor do que 1). Em 2002 nenhuma outra variável foi estatisticamente significativa. Em 2006, a renda familiar se mostrou estatisticamente relevante no Modelo 1 (aumentando a renda diminuía a adesão à democracia), mas não no Modelo 2. O inverso acontecia com escolaridade, que mostrou-se significativa no Modelo 2 (a adesão à democracia aumentava com a escolaridade), mas não no Modelo 1. Em 2010 nenhuma outra variável, com exceção dos sentimentos partidários mostrou-se estatisticamente significativa.

\section{Sentimentos partidários e estatismo}

Para analisarmos as possíveis associações entre os sentimentos partidários dos eleitores e a dimensão atitudinal associada ao tema da intervenção do Estado na economia, dimensão que chamamos de "estatismo", foi criado um índice a partir das respostas a quatro questões (ver Apêndice Metodológico 1). Este índice é utilizado nas análises a seguir. Como não havia as mesmas questões nos ESEB 
RIBEIRO, E.; CARREIRÃO, Y.; BORBA, J. Sentimentos partidários e atitudes políticas...

2002 e 2006, fiou inviabilizada a comparação entre as três pesquisas. A Tabela 7 mostra as associações entre o índice de estatismo e os sentimentos partidários dos eleitores no ESEB 2010.

A associação é relativamente fraca, mas é no sentido esperado: eleitores com "preferência" pelo PT têm inclinações mais estatistas, enquanto eleitores com "preferência" pelo PSDB têm inclinações menos estatistas (associação negativa). Isso é confirmado também quando é utilizado como indicador dos sentimentos partidários a variável que considera sentimentos positivos e negativos para PT e PSDB simultaneamente. O sinal negativo do coeficiente de associação se deve ao fato de que a escala caminha dos eleitores com "preferência" pelo PT e rejeição ao PSDB para aqueles com "preferência" pelo PSDB e rejeição ao PT.

Tabela 7

Associações (Gamma) entre sentimentos partidários e estatismo (2010)

\begin{tabular}{|c|c|c|c|}
\hline & PT & PSDB & Sentimentos PT/PSDB \\
\hline Índice de Estatismo & $0,15^{*}$ & $-0,23^{*}$ & $-0,16^{*}$ \\
\hline
\end{tabular}

Fonte: ESEB 2010.

Nota: ${ }^{*}$ sig $<0,05$.

A Tabela 8 apresenta os dados de modelos de regressão linear múltipla tomando o índice de estatismo como variável dependente, modelos similares aos apresentados para as atitudes em relação à democracia ${ }^{18}$.

\footnotetext{
18 Utilizamos regressão linear múltipla porque a variável dependente (índice de estatismo) é uma variável escalar. O mesmo tipo de análise será usado para outras variáveis dependentes escalares.
} 
Tabela 8

Modelo linear para o Índice de Estatismo (2010)

\begin{tabular}{|c|c|c|c|c|c|c|}
\hline \multirow[t]{2}{*}{ Variável } & \multicolumn{3}{|c|}{ Modelo 1} & \multicolumn{3}{|c|}{ Modelo 2} \\
\hline & B & Beta & Sig. & B & Beta & Sig. \\
\hline Sexo & $\cdot, 215$ &,- 036 & ,248 &,- 200 & $\cdot, 034$ & 277 \\
\hline Faixa de Idade &,- 049 &,- 025 & ,463 &,- 044 &,- 022 &, 515 \\
\hline Escolaridade & 044 &, 034 & ,362 &, 053 & ,041 &, 272 \\
\hline Faixa de renda familiar & $\cdot, 346$ &,- 158 &, 000 &,- 340 & $\cdot, 155$ &, 000 \\
\hline Autoposicionamento Ideológico &,- 039 &,- 043 &, 186 & -029 &,- 032 &, 313 \\
\hline Sentimentos Positivos pelo PT & 1,034 &, 170 &, 000 & & & \\
\hline Sentimentos Positivos pelo PSDB & $\cdot, 683$ &,- 078 & ,018 & & & \\
\hline Sentimentos PT/PSDB & & & &,- 394 & .234 &, 000 \\
\hline $\mathrm{R}^{2}$ & \multicolumn{3}{|c|}{ 074, } & \multicolumn{3}{|c|}{087} \\
\hline
\end{tabular}

Fonte: ESEB 2010.

De forma similar aos modelos anteriores, os $\mathrm{R}^{2}$ são baixos, indicando que os modelos explicam uma pequena parte da variação da variável dependente. De toda forma, a análise multivariada corrobora os achados da análise bivariada: há associações estatisticamente significativas com os sentimentos partidários, no mesmo sentido encontrado na Tabela 9: positiva com o PT e negativa com o PSDB (e com a variável "Sentimentos PT/PSDB). Além dos sentimentos partidários, a única variável que mostrou associação estatisticamente significativa com o índice de estatismo foi a faixa de renda familiar: quanto maior a renda, menor o índice de estatismo.

\section{Sentimentos partidários e igualitarismo}

Várias questões do ESEB 2010 estavam relacionadas com as disposições dos entrevistados acerca da igualdade social e econômica, dimensão atitudinal que chamamos de "igualitarismo". Partimos, inicialmente, de sete questões. A análise fatorial, porém, revelou que nem todas as questões faziam parte de uma mesma medida latente que pudesse expressar aquelas disposições. Diante desse resultado, optamos por utilizar quatro questões, que compunham um mesmo fator. Algumas recodificações foram necessárias para tentarmos construir um índice adequado. $O$ índice assim criado (ver Apêndice Metodológico 2) foi utilizado nas análises a 
RIBEIRO, E.; CARREIRÃO, Y.; BORBA, J. Sentimentos partidários e atitudes políticas...

seguir. Da mesma forma como para a medida de estatismo, não havia questões semelhantes às utilizadas para criar o índice de igualitarimo no ESEB 2002 e 2006, razão pela qual não foi possível comparar as três pesquisas.

Tabela 9

Associações/Correlações entre sentimentos partidários e igualitarismo (Gamma/Pearson) (2010)

\begin{tabular}{|c|c|c|}
\hline PT (Gamma) & PSDB (Gamma) & Sentimentos PT/PSDB (Pearson) \\
\hline $0,09^{*}$ & 0,03 & $-0,07^{*}$ \\
\hline
\end{tabular}

Fonte: ESEB 2010.

Nota: * sig<0,05.

Como vemos na Tabela 9, não há associação estatisticamente significativa entre sentimentos partidários positivos em relação ao PSDB e o índice de igualitarismo. Já no que diz respeito à "preferência" pelo PT, a associação embora fraca, é estatisticamente significativa e positiva, ou seja, eleitores do PT têm tendência levemente maior a manifestarem atitudes igualitárias, comparativamente aos eleitores sem preferência pelo partido. A associação negativa encontrada com o indicador que engloba os sentimentos positivos e negativos em relação ao $\mathrm{PT}$ e ao PSDB simultaneamente, indica que o igualitarismo aumenta levemente à medida que passamos da posição extrema da escala onde se encontram os eleitores que simultaneamente têm preferência pelo PT e rejeitam o PSDB, para o outro extremo da escala, onde estão os eleitores que simultaneamente têm preferência pelo PSDB e rejeitam o $\mathrm{PT}$.

Quando incluímos outras variáveis, embora o grau de explicação do modelo seja baixo, a análise de regressão linear (Tabela 10) apresenta significância estatística dos sentimentos partidários, nos dois modelos (ou seja, para os dois tipos de indicadores de sentimentos partidários aqui utilizados). Para os sentimentos positivos em relação ao PT e para o indicador do Modelo 2 (Sentimentos PT/PSDB) o sentido é o mesmo encontrado na análise bivariada. No caso dos sentimentos positivos em relação ao PSDB, o coeficiente é positivo, indicando que o os eleitores com preferência pelo PSDB tendem a ter atitudes mais igualitárias, comparados aos eleitores sem preferência pelo partido. Com exceção da renda familiar, que no Modelo 1 se aproxima do nível de significância de 0,05 
(sendo que o igualitarismo diminui com o aumenta da renda familiar), nenhuma outra variável teve influência significativa sobre o índice de igualitarismo.

Tabela 10

Modelo linear para o Índice de Igualitarismo (2010)

\begin{tabular}{|c|c|c|c|c|c|c|}
\hline \multirow[t]{2}{*}{ Variável } & \multicolumn{3}{|c|}{ Modelo 1} & \multicolumn{3}{|c|}{ Modelo 2} \\
\hline & B & Beta & Sig. & $\mathrm{B}$ & Beta & Sig. \\
\hline Sexo &, 213 &, 037 &, 238 & ,237 & ,042 &, 190 \\
\hline Faixa de Idade & - & - &, 322 & - & . &, 332 \\
\hline Escolaridade & . & . & ,687 & . & . & ,800 \\
\hline Faixa de renda familiar & - & - &, 052 & - & - & ,084 \\
\hline Autoposicionamento & - & - & ,298 & - & - &, 557 \\
\hline Sentimentos Positivos pelo PT &, 569 & 097 &, 003 & & & \\
\hline Sentimentos Positivos pelo &, 613 &, 069 &, 034 & & & \\
\hline Sentimentos PT/PSDB & & & &,- 127 &,- 077 &, 016 \\
\hline $\mathbf{R}^{2}$ & \multicolumn{3}{|c|}{,020 } & \multicolumn{3}{|c|}{,015 } \\
\hline
\end{tabular}

Fonte: ESEB 2010.

\section{Sentimentos partidários e aceitação da repressão ou censura}

Duas outras medidas atitudinais foram criadas a partir do ESEB 2010: uma medida de aceitação, por parte dos eleitores, de ações do governo no sentido de reprimir passeatas e manifestações e uma medida de aceitação do direito do governo censurar meios de comunicação ${ }^{19}$.

Como se vê na Tabela 11, há associação positiva, fraca, mas estatisticamente significativa, entre "preferência" pelo PT e aceitação da censura. Ou seja, eleitores com preferência pelo PT tendem a aceitar a censura aos meios de comunicação um pouco mais do que os que não têm essa preferência. Também há

\footnotetext{
19 As questões utilizadas foram, respectivamente: "quando uma manifestação ou passeata passa dos limites, o governo deve ter o direito de acabar com ela, inclusive usando a polícia" (ESEB 98 b - V207) e "o Governo deve ter o direito de censurar jornais, TVs e rádios quando eles passam dos limites" (ESEB 98 - V211). As duas tinham como opções de resposta: “1) Concorda muito; 2) Concorda um pouco; 3) Discorda um pouco; 4) Discorda muito". As respostas foram recodificadas de forma a gerar uma variável dicotômica (concorda/discorda).
} 
RIBEIRO, E.; CARREIRÃO, Y.; BORBA, J. Sentimentos partidários e atitudes políticas...

associações positivas significativas de magnitude um pouco maior entre PSDB e as duas medidas, de aceitação da repressão e da censura; eleitores com "preferência" pelo PSDB aceitam a repressão e a censura em maior grau do que os eleitores que não têm essa preferência. Provavelmente essas tendências fazem com que se anule, parcialmente, a associação entre aceitação da censura e o indicador de sentimentos partidários que inclui todos os sentimentos em relação aos dois partidos simultaneamente - embora no que se refira à aceitação da repressão a passeatas e manifestações essa explicação para uma associação quase nula não possa ser explicada dessa forma, já que a associação com o PT é nula.

\section{Tabela 11}

Associações entre sentimentos partidários e aceitação da repressão e da censura (Gamma) (2010)

\begin{tabular}{|l|c|c|c|}
\hline & PT & PSDB & Sentimentos \\
\hline Aceitação da repressão a passeatas e & .000 & $.237^{*}$ & .033 \\
\hline Aceitação da censura & $.143^{*}$ & $.231^{*}$ &. .028 \\
\hline
\end{tabular}

Fonte: ESEB 2010

Nota: * sig<0,05.

Embora mais uma vez os pseudo- $\mathrm{R}^{2}$ sejam muito baixos, a análise de regressão logística (Tabela 12) corrobora os achados da Tabela 11: associação estatisticamente significativa apenas com sentimentos positivos em relação ao PSDB. As associações com o PT, no Modelo 1 e com PT/PSDB no Modelo 2 são estatisticamente não-significativas. Nos dois modelos, a escolaridade e o autoposicionamento ideológico dos eleitores mostraram-se significativos, da mesma forma. A aceitação da repressão a manifestações e passeatas aumenta com a escolaridade dos eleitores (o que não era teoricamente esperado) e à medida que passamos dos eleitores posicionados mais à esquerda para os posicionados mais à direita, nos dois modelos. 
OPINIÃO PÚBLICA, Campinas, vol. 17, n², Novembro, 2011, p.333-368

Tabela 12

Modelo logístico para Aceitação da Repressão (2010)

\begin{tabular}{|l|c|c|c|c|}
\hline & Modelo 1 & \multicolumn{2}{l|}{ Modelo 2 } \\
\hline Variável & $\operatorname{Exp}(\mathrm{B})$ & Sig. & $\operatorname{Exp}(\mathrm{B})$ & Sig. \\
\hline Sexo & 1.036 & .789 & 1.045 & .741 \\
\hline Faixa de Idade & 1.088 & .079 & 1.087 & .084 \\
\hline Escolaridade & 1.071 & .048 & 1.071 & .048 \\
\hline Faixa de renda familiar & 1.043 & .463 & 1.049 & .396 \\
\hline Autoposicionamento Ideológico & 1.047 & .030 & 1.052 & .015 \\
\hline Sentimentos Positivos pelo PT & 1.163 & .278 & & \\
\hline Sentimentos Positivos pelo PSDB & 1.706 & .019 & & \\
\hline Sentimentos PT/PSDB & \multicolumn{3}{|l|}{1.025} & .530 \\
\hline Nagelkerke R & \multicolumn{3}{|c|}{025} & \multicolumn{3}{|c|}{} \\
\hline
\end{tabular}

Fonte: ESEB 2010.

No que se refere ao indicador de aceitação à censura aos meios de comunicação, os dados da Tabela 13 também corroboram os resultados encontrados na Tabela 11.

Tabela 13

Modelo logístico para Aceitação da Censura (2010)

\begin{tabular}{|l|c|c|c|c|}
\hline \multirow{2}{*}{ Variável } & \multicolumn{2}{|c|}{ Modelo 1 } & \multicolumn{2}{c|}{ Modelo 2 } \\
\cline { 2 - 5 } & $\operatorname{Exp}(\mathrm{B})$ & Sig. & $\operatorname{Exp}(\mathrm{B})$ & Sig. \\
\hline Sexo & 1.330 & .028 & 1.346 & .021 \\
\hline Faixa de Idade & 1.016 & .731 & 1.016 & .743 \\
\hline Escolaridade & .896 & .001 & .899 & .002 \\
\hline Faixa de renda familiar & .969 & .563 & .979 & .693 \\
\hline Autoposicionamento Ideológico & 1.026 & .217 & 1.034 & .103 \\
\hline Sentimentos Positivos pelo PT & 1.331 & .036 & & \\
\hline Sentimentos Positivos pelo PSDB & 1.984 & .001 & & \\
\hline Sentimentos PT/PSDB & \multicolumn{3}{|c|}{1.013} & .730 \\
\hline Nagelkerke R & \multicolumn{3}{|c|}{053} & \multicolumn{3}{|c|}{037} \\
\hline
\end{tabular}

Fonte: ESEB 2010. 
Nesse caso, os sentimentos positivos em relação ao PT e ao PSDB, isoladamente, são estatisticamente significativos, enquanto o indicador de sentimentos partidários utilizado no modelo 2 não é. Ressalve-se que os modelos têm baixa capacidade explicativa, dados os baixos pseudo- $R^{2}$. E, aqui, apenas a escolaridade tem coeficiente estatisticamente significativo, nos dois modelos, mas agora no sentido teoricamente esperado: diminui a aceitação da censura à medida que aumenta a escolaridade dos eleitores.

\section{Sentimentos partidários e voto}

Até aqui foram analisadas as relações entre os sentimentos partidários e variáveis atitudinais dos eleitores. Esta seção analisa a relação entre os sentimentos partidários e uma variável comportamental: o voto dos eleitores em 2010. Nesse caso, partimos diretamente para análise multivariada dos dados, pois a realização de testes de associação iria demandar a binarização dos votos para cada um dos candidatos, o que não seria de grande utilidade para o presente estudo. Analisamos essas relações a partir de modelos de regressão logística. É importante assinalar que o objetivo não é elaborar um modelo completo e sofisticado de explicação de voto, mas, sim, verificar se os sentimentos partidários se constituem em preditores de voto em um modelo simples, com basicamente as mesmas variáveis utilizadas até aqui ${ }^{20}$.

Apresentamos a seguir dois modelos: um com as variáveis binárias com os sentimentos positivos em relação ao PT e ao PSDB, respectivamente, e o segundo tomando como indicador dos sentimentos partidários a variável que inclui os sentimentos positivos e negativos relativos aos dois partidos simultaneamente. Em cada análise aparecem os dados referentes a Serra, a Marina e aos outros candidatos. A categoria de referência é sempre o voto em Dilma ${ }^{21}$.

A Tabela 14 apresenta o primeiro modelo, com os sentimentos partidários positivos em relação ao PT e ao PSDB, separadamente. Inicialmente, cabe destacar que o $\mathrm{R}^{2}$ de Nagelkerke foi de 0,409, valor bem superior aos encontrados em todos os modelos anteriores. Com relação ao candidato José Serra, cada avanço na escala

20 Estudo específico sobre a decisão de voto, mais aprofundado, incluindo outras variáveis e compreendendo também dados dos ESEB 2002 e 2006 será objeto de outro trabalho a ser desenvolvido pelos autores.

${ }^{21}$ A variável voto ( $1^{\circ}$ turno) foi assim operacionalizada: 1 - Dilma; 2 - Serra; 3 - Marina; 4 - Outros (Eymael, Ivan Pinheiro, Levy Fidelix, Plínio, Rui C. Pimenta, Zé Maria); Missing - anulou/branco/Não Sabe/ não lembra/não respondeu/não se aplica. 
de posicionamento ideológico eleva em 9,1\% a chance de o eleitor votar em Serra, comparando com a probabilidade de votar em Dilma (categoria de referência). Quando comparados aos que manifestam sentimentos positivos pelo PT, aqueles que não manifestam tais sentimentos têm $1.544 \%$ mais chance de votar em Serra do que de votar em Dilma. Quando comparados aos que possuem sentimentos positivos pelo PSDB, aqueles que não manifestam tais sentimentos têm 89,8\% menos chance de votar em Serra do que votar em Dilma. As demais variáveis não se mostraram relevantes.

Tabela 14

Modelo logístico 1 para Voto ( $1^{\circ}$ turno - 2010)

\begin{tabular}{|c|c|c|c|c|c|}
\hline Voto $1^{\circ}$ Turno & Variáveis & B & Wald & Sig. & $\operatorname{Exp}(B)$ \\
\hline \multirow{11}{*}{ Serra } & Intercepto & -1.173 & 3.065 & .080 & \\
\hline & FXIDADE & .050 & .555 & .456 & .952 \\
\hline & ESC & .068 & 2.000 & .157 & 1.070 \\
\hline & FXRENDAF & .009 & .014 & .905 & 1.009 \\
\hline & Autoposicionamento ideológico & .087 & 8.100 & .004 & 1.091 \\
\hline & {$[\mathrm{SEXO}=1]$} & .033 & .033 & .856 & .968 \\
\hline & {$[\mathrm{SEXO}=2]$} & $0^{\mathrm{b}}$ & . & . & . \\
\hline & [SPPTDic=0] & 2.800 & 126.459 & .000 & 16.444 \\
\hline & [SPPTDic=1] & $0^{\mathrm{b}}$ & . & . & . \\
\hline & [SPPSDBDic=0] & -2.285 & 43.975 & .000 & .102 \\
\hline & [SPPSDBDic=1] & $0^{\mathrm{b}}$ & . & . & . \\
\hline \multirow{11}{*}{ Marina } & Intercepto & -3.108 & 19.529 & .000 & \\
\hline & FXIDADE & -.105 & 2.549 & .110 & .900 \\
\hline & ESC & .272 & 29.909 & .000 & 1.312 \\
\hline & FXRENDAF & .142 & 3.759 & .053 & 1.153 \\
\hline & Autoposicionamento ideológico & .043 & 2.077 & .149 & 1.044 \\
\hline & {$[\mathrm{SEXO}=1]$} & -.156 & .716 & .397 & .856 \\
\hline & {$[\mathrm{SEXO}=2]$} & $0^{\mathrm{b}}$ & . & . & . \\
\hline & [SPPTDic=0] & 1.716 & 73.669 & .000 & 5.564 \\
\hline & [SPPTDic=1] & $0^{\mathrm{b}}$ & . & . & . \\
\hline & [SPPSDBDic=0] &. .527 & 1.557 & .212 & .591 \\
\hline & {$[$ SPPSDBDic $=1]$} & $0^{\mathrm{b}}$ & . & 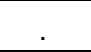 & . \\
\hline
\end{tabular}


RIBEIRO, E.; CARREIRÃO, Y.; BORBA, J. Sentimentos partidários e atitudes políticas...

\begin{tabular}{|c|c|c|c|c|c|}
\hline \multirow{11}{*}{ Outros } & Intercepto & .5 .075 & 5.035 & .025 & \\
\hline & FXIDADE & .629 & 7.449 & .006 & .533 \\
\hline & ESC & .222 & 1.588 & .208 & 1.248 \\
\hline & FXRENDAF & .131 & .301 & .583 & 1.140 \\
\hline & Autoposicionamento ideológico & .139 & 1.846 & .174 & 1.150 \\
\hline & {$[\mathrm{SEXO}=1]$} & .196 & .111 & .739 & 1.217 \\
\hline & [SEXO=2] & $0^{\mathrm{b}}$ & . & . & . \\
\hline & [SPPTDic=0] & 2.360 & 8.913 & .003 & 10.587 \\
\hline & [SPPTDic=1] & $0^{\mathrm{b}}$ & & . & . \\
\hline & [SPPSDBDic=0] & .460 & .168 & .682 & .631 \\
\hline & [SPPSDBDic=1] & $0^{b}$ & & & . \\
\hline
\end{tabular}

Fonte: ESEB 2010. Nagelkerke $\mathrm{R}^{2}=0.497$.

a. The reference category is: Dilma.

b. This parameter is set to zero because it is redundant.

Quanto à candidata Marina Silva, a escolaridade passa a ser um preditor relevante. Cada nível de escolaridade adicional aumenta em $31,2 \%$ a chance de o eleitor votar nessa candidata, em comparação com a chance de votar em Dilma. A faixa de renda também se torna importante (se considerarmos que o nível de significância de 0,053 é muito próximo do valor limite estabelecido, de 0,05). Nesse caso cada elevação na faixa de renda familiar eleva em 15,3\% a chance de votar em Marina, comparada com a chance de votar em Dilma. Quando comparados aos que manifestam sentimentos positivos pelo PT, aqueles que não manifestam tais sentimentos têm $456,4 \%$ mais chance de votar em Marina do que de votar em Dilma. Todas as demais variáveis não se mostraram relevantes, inclusive os sentimentos positivos pelo PSDB.

Considerando todos os "outros candidatos" em conjunto (Eymael, Ivan Pinheiro, Levy Fidelix, Plínio, Rui C. Pimenta, Zé Maria), cada elevação na faixa etária reduz em $46,7 \%$ a chance de o eleitor votar em "outro candidato", comparando com a chance de votar em Dilma. Quando comparados aos que manifestam sentimentos positivos pelo PT, aqueles que não manifestam tais sentimentos têm $958,7 \%$ mais chance de votar em outros candidatos do que de votar em Dilma. Todas as demais variáveis não foram relevantes, inclusive os sentimentos positivos em relação ao PSDB.

$\mathrm{Na}$ Tabela 15 são apresentados os resultados para o modelo 2, que utiliza como indicador de sentimento partidários o conjunto de sentimentos (positivos e negativos) relativos ao PT e ao PSDB simultaneamente. Novamente, o $\mathrm{R}^{2}$ de 
Nagelkerke $(0,497)$ foi bem superior aos encontrados em todos os modelos construídos para as variáveis atitudinais, sendo inclusive superior ao do modelo anterior para o voto. Ou seja, modelos com as variáveis aqui incluídas "explicam" bem mais o voto do que as atitudes dos eleitores aqui em estudo.

Os dados indicam que cada avanço na escala de posicionamento ideológico aumenta em 9\% a chance de votar em Serra, comparada com a chance de votar em Dilma. Cada avanço na escala de sentimentos partidários eleva em 302,9\% a chance de votar em Serra, comparada com a chance de votar em Dilma. As demais variáveis não se mostraram relevantes para explicar o voto em Serra.

Com relação a Marina Silva, cada elevação na escolaridade aumenta em $30,4 \%$ a chance de votar na candidata, em comparação com a probabilidade de votar em Dilma. Elevação na faixa de renda aumenta essa chance em 15,4\% (considerando que o nível de probabilidade encontrado é muito próximo de 0,05). Elevações na escala de sentimentos partidários produzem elevação de 101,5\% nessa chance. 
RIBEIRO, E.; CARREIRÃO, Y.; BORBA, J. Sentimentos partidários e atitudes políticas...

Tabela 15

Modelo logístico 2 para Voto $\left(1^{\circ}\right.$ turno - 2010)

\begin{tabular}{|c|c|c|c|c|c|}
\hline $\begin{array}{l}\text { Voto } 1^{\circ} \\
\text { Turno }\end{array}$ & Variáveis & B & Wald & Sig. & $\operatorname{Exp}(B)$ \\
\hline \multirow[t]{8}{*}{ Serra } & Intercepto & .5 .896 & 86.726 & .000 & \\
\hline & FXIDADE & -.095 & 1.716 & .190 & .909 \\
\hline & ESC & .044 & .692 & .405 & 1.045 \\
\hline & FXRENDAF & .009 & .011 & .916 & 1.009 \\
\hline & Autoposicionamento ideológico & .086 & 6.448 & .011 & 1.090 \\
\hline & SentPTPSDB & 1.394 & 245.580 & .000 & 4.029 \\
\hline & {$[\mathrm{SEXO}=1]$} & .019 & .009 & .924 & 1.019 \\
\hline & {$[\mathrm{SEXO}=2]$} & $\mathrm{O}^{\mathrm{b}}$ & & & \\
\hline \multirow[t]{8}{*}{ Marina } & Intercepto & .4 .571 & 65.247 & .000 & \\
\hline & FXIDADE & -.122 & 3.324 & .068 & .885 \\
\hline & ESC & .266 & 28.004 & .000 & 1.304 \\
\hline & FXRENDAF & .144 & 3.769 & .052 & 1.154 \\
\hline & Autoposicionamento ideológico & .039 & 1.658 & .198 & 1.040 \\
\hline & SentPTPSDB & .700 & 98.917 & .000 & 2.015 \\
\hline & {$[\mathrm{SEXO}=1]$} & .092 & .243 & .622 & .912 \\
\hline & {$[\mathrm{SEXO}=2]$} & $0^{b}$ & 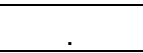 & & \\
\hline \multirow[t]{8}{*}{ Outros } & Intercepto & .6 .397 & 12.606 & .000 & \\
\hline & FXIDADE &. .652 & 7.938 & .005 & .521 \\
\hline & ESC & .204 & 1.316 & .251 & 1.226 \\
\hline & FXRENDAF & .125 & .275 & .600 & 1.133 \\
\hline & Autoposicionamento ideológico & .128 & 1.586 & .208 & 1.136 \\
\hline & SentPTPSDB & .863 & 18.010 & .000 & 2.369 \\
\hline & {$[\mathrm{SEXO}=1]$} & .273 & .214 & .644 & 1.314 \\
\hline & {$[\mathrm{SEXO}=2]$} & $0^{b}$ & & & \\
\hline
\end{tabular}

Fonte: ESEB 2010. Nagelkerke $\mathrm{R}^{2}=0.497$.

a. The reference category is: Dilma.

b. This parameter is set to zero because it is redundant.

Quanto aos "outros candidatos", elevações na faixa de idade levam a uma queda de 47,9\% na chance de voto (comparando com Dilma). Elevações na escala de sentimentos partidários produzem elevação de $136,9 \%$ na chance de votar nesses "outros" candidatos, comparativamente a votar em Dilma. Os coeficientes relativos às outras variáveis não têm significância estatística. 
Uma das variáveis mais relevantes na decisão de voto para presidente no Brasil tem sido a avaliação que os eleitores fazem do desempenho do governo em exercício (LAVAREDA, 1989; MENDES e VENTURI, 1994; CARREIRÃO, 2002 e 2007; ALMEIDA, 2008; LAVAREDA, 2009, entre outros). Testamos estes mesmos modelos acima, incluindo essa variável (operacionalizada como uma escala de "péssimo" a "ótimo"). Para os dois modelos os resultados foram, sinteticamente, os seguintes: houve um incremento dos pseudo- $R^{2}(0,455$ e 0,522 para os modelos 1 e 2 acima, respectivamente), indicando que a inclusão da variável aprimora o modelo. Mas, sua inclusão não afetou significativamente os coeficientes das demais. Nos dois modelos, "avaliação de governo" foi relevante para o voto em Serra e Marina: a chance de votar nesses candidatos cai consideravelmente à medida que, na avaliação que os eleitores faziam do governo do presidente Lula nos deslocamos da avaliação "péssimo" para a avaliação "ótimo". Para os "outros candidatos", essa variável foi relevante apenas no modelo 1 . De toda forma, a variável "sentimentos partidários" mantém sua enorme influência nos dois modelos e para todos os candidatos, com a única exceção dos sentimentos positivos em relação ao PSDB na explicação do voto dos "outros candidatos" - da mesma forma como acontece no modelo 1 , sem a variável "avaliação de governo".22

Concluindo, essa análise relativa aos impactos dos sentimentos partidários dos eleitores sobre seu voto, é possível afirmar que, nos modelos aqui testados, com ou sem a inclusão da variável "avaliação de governo", essa foi uma medida com influência muito forte sobre a decisão de voto dos eleitores. Os modelos mostraram um poder explicativo bem maior do que os relativos às variáveis atitudinais.

\section{Considerações finais}

Considerando o caráter representativo das democracias contemporâneas, os partidos são as principais instituições a desempenhar a função de mediação entre os eleitores e o sistema político. No que se refere especificamente à decisão de voto, Downs (1957) tratou dessa dimensão, na medida em que situou os partidos como produtores de atalhos informacionais aos eleitores. Os programas partidários, dessa forma, diminuiriam os custos de informação sobre os complexos temas do mundo político.

\footnotetext{
22 Não apresentamos as tabelas correspondentes para não sobrecarregar o texto.
} 
Buscamos verificar no presente trabalho como se relacionam as dimensões dos sentimentos partidários, das atitudes e comportamento político dos eleitores. Conforme vimos na introdução, parte da literatura aponta que a chegada do PT à Presidência da República teria gerado mudanças em termos das bases sociais e no próprio sistema de crenças do eleitorado (VEIGA, 2007; CARREIRÃO, 2008).

Os resultados de nossa pesquisa indicam que, em 2010, os sentimentos partidários (em especial os sentimentos de identificação com PT e PSDB) estavam relacionados, sim, com atitudes e comportamentos, porém a intensidade com que os sentimentos afetavam atitudes (caso seja esse o sentido da relação causal entre as variáveis) era bem menor que a intensidade com que eles afetavam o comportamento político (decisão do voto) ${ }^{23}$. Vimos que sentimentos positivos em relação ao PT estiveram relacionados positivamente com adesão à democracia, defesa de um papel maior para o Estado, igualitarismo e aceitação à censura em determinadas situações. Já sentimentos positivos relativos ao PSDB estiveram associados negativamente à adesão à (e preferência pela) democracia, ao estatismo e positivamente com igualitarismo e aceitação da repressão e censura. Quanto ao indicador de sentimentos partidários que agrega o conjunto de sentimentos positivos e negativos relativos ao PT e ao PSDB simultaneamente, apresentou associações negativas com adesão à (e preferência por) democracia, estatismo, e igualitarismo. Ou seja, à medida que passamos dos eleitores com preferência pelo PT e rejeição ao PSDB (simultaneamente) para os eleitores com preferência pelo PSDB e rejeição pelo PT (simultaneamente), diminui a adesão à democracia, o apreço por atitudes igualitárias e por uma maior intervenção do estado na economia. Não houve associações significativas entre esse indicador de sentimentos partidários e as variáveis atitudinais relacionadas à aceitação da repressão e da censura. De toda forma, é preciso destacar que os modelos de regressão apresentaram baixa capacidade explicativa para o conjunto de variáveis atitudinais em questão.

Com relação à dimensão do comportamento político, os sentimentos partidários também se mostraram associados e significativos na explicação do voto em 2010, só que em uma intensidade bem mais forte, que se refletiu na capacidade explicativa dos modelos de regressão construídos. Dessa forma, o que se depreende

\footnotetext{
${ }^{23}$ Essas conclusões sobre as associações entre sentimentos partidários e variáveis atitudinais baseiam. se nos resultados das análises multivariadas, já que aí a inclusão de outras variáveis foi utilizada como estratégia de controle.
} 
é que temos partidos fracos como estruturadores de atitudes ${ }^{24}$ (de adesão à democracia, igualitarismo, estatismo, tolerância à corrupção e aceitação da censura), mas relativamente fortes na estruturação do comportamento eleitoral ${ }^{25}$. Uma primeira observação na direção da interpretação de tais resultados é que as variáveis atitudinais em questão são bastante complexas e exigiriam modelos mais refinados que incorporassem até mesmo dimensões relacionadas à personalidade do indivíduo (MONDAK et al, 2010; VECHIONE \& CAPRARA, 2009). Já no que diz respeito à decisão do voto, embora no Brasil não haja consenso sobre o papel dos partidos, os nossos resultados parecem indicar que eles representam um atalho informacional relevante para os eleitores, pelo menos nas eleições presidenciais.

Do ponto de vista da dimensão temporal, tentamos testar com os dados para 2010 a hipótese corroborada na análise de Carreirão (2008) de que as opiniões políticas dos eleitores que manifestam sentimentos por diferentes partidos eram mais diferenciadas entre si em momento mais próximo do início do atual sistema partidário (em nosso caso, 2002) do que em período recente (em nosso caso, 2010). A comparação entre o ESEB de 2002, 2006 e 2010, porém, ficou prejudicada pelo fato de as perguntas utilizadas para mensurar atitudes dos eleitores não serem as mesmas nas três pesquisas ${ }^{26}$.

Outra tentativa foi feita no sentido de comparar os resultados aqui encontrados com os dados de 1990, utilizados por Carreirão (2008), de forma a verificar se a tendência encontrada por aquele autor, com dados até 2007, se mantinha em 2010. Novamente isso não foi possível, porque tanto as questões usadas para mensurar as atitudes dos eleitores, como os indicadores para "sentimentos partidários" eram diferentes nos dois momentos (1990 e 2010). A impossibilidade de comparação dos níveis de associação entre sentimentos

24 É importante fazer novamente a ressalva de que a relação de causalidade entre sentimentos partidários e atitudes políticas pode acontecer no sentido inverso ao que estamos pressupondo aqui, ou seja, primeiro as pessoas constituiriam suas crenças e atitudes políticas para depois fazer suas escolhas partidárias; aliás, esse é o ponto de partida das teorias da cultura política. Como o problema da direção da causalidade não pode ser resolvido com o tipo de dados que estamos lidando, temos ai um limite analítico do presente estudo. De toda forma, supondo essa relação de cusalidade, a capacidade dos partidos de estruturar atitudes seria fraca.

25 Também aqui é importante destacar que as fortes associações com o voto foram encontradas para o PT e o PSDB, nas eleições presidenciais, onde a vinculação entre eleitores e esses partidos é mais clara, ou seja, a inclusão de outros partidos ou eleições para cargos que não o de presidente poderia produzir resultados bastante distintos dos que encontramos aqui.

26 Essa foi uma limitação não esperada no início do trabalho, já que a expectativa era a de que as perguntas dos diferentes ESEB fossem semelhantes entre si, de forma a permitir análise de séries históricas relativas às variáveis atitudinais. 
RIBEIRO, E.; CARREIRÃO, Y.; BORBA, J. Sentimentos partidários e atitudes políticas...

partidários e atitudes dos eleitores ao longo do tempo frustrou a realização de um dos principais objetivos que motivou o presente trabalho.

De toda forma, acreditamos que os resultados da análise aqui realizada indicam: primeiro, que há algumas diferenças interessantes de atitudes relativas a temas políticos relevantes entre eleitores que manifestam sentimentos em relação aos dois principais partidos brasileiros (no que se refere a seu papel estruturador das disputas presidenciais) e, segundo, que esses sentimentos estão, ainda, fortemente associados ao voto para presidente.

Por fim, em que pesem os limites de nosso estudo, acreditamos que as relações entre sentimentos partidários, atitudes e comportamento eleitoral devam ser exploradas por outras perspectivas de análise, pois ainda sabemos pouco sobre os partidos e sua relação com o sistema de crenças políticas do eleitorado. Essa questão pôde ser verificada em nosso estudo, onde nossos modelos foram muito mais robustos para explicar o voto do que para explicar as atitudes políticas. Explorar essa disjuntiva pode ser uma possibilidade de obter avanços analíticos na interpretação da configuração e dos rumos do atual sistema partidário brasileiro.

\section{Referências Bibliográficas}

ALMEIDA, A. A cabeça do eleitor: estratégia de campanha, pesquisa e vitória eleitoral. Rio de Janeiro: Record, 2008.

BRAGA, M. S. "Eleições e democracia no Brasil: a caminho de partidos e sistema partidário institucionalizados". Revista Brasileira de Ciência Política, nº. 4, 2010.

CARREIRÃO, Y.; KINZO, M. D. "Partidos políticos, preferência partidária e decisão eleitoral no Brasil (1989/2002)". Dados, vol.47, n.1, 2004.

CARREIRÃO, Y. "Relevant factors for the voting decision in the 2002 presidential election: an analysis of the ESEB (Brazilian Electoral Study) Data". Brazilian Political Science Review, vol.1, $\mathrm{n}^{\circ} .1,2007$.

. "Opiniões políticas e sentimentos partidários dos eleitores brasileiros". Opinião

Pública, vol.14, n² 2, p.319-351,2008.

CASTRO, M.M. "Sujeito e estrutura no comportamento eleitoral". Revista Brasileira de Ciências Sociais, $\mathrm{n}^{\circ} 20,1992$. 
CLARKE, H.; STEWART, M. "The decline of the parties in the minds of citizens". Annual Review of Political Science, vol.1, 1998.

DALTON, R. WATTENBERG, M. The Not So Simple Act of Voting. In: Finifter, A. (ed.). State of Political Science II. Washington: American Political Science Association, 1993.

(eds.). Parties without partisans: political change in advanced industrialized democracies. Oxford: Oxford University Press, 2001.

DOWNS, A. An economic theory of democracy. New York: Harper \& Row Publishers, 1957.

FIGUEIREDO, M. A decisão do voto. São Paulo: IDESP/Sumaré, 1991.

FIORINA, M. Retrospective voting in American national elections. New Haven: Yale University Press, 1981.

HUNTER, W.; POWER, T. "Rewarding Lula: Executive power, social policy, and the Brazilian elections of 2006". Latin American Politics \& Society, vol. 49, n 1, Spring, p.1-30, 2007.

KINZO, M. D. "Os partidos no eleitorado: percepções públicas e laços partidários no Brasil". Revista Brasileira de Ciências Sociais, vol.19, n 54, 2005.

LAMOUNIER , B.; MENEGUELLO, R. Partidos políticos e consolidação democrática. O caso brasileiro. São Paulo: Brasiliense, 1986.

LAVAREDA, A. "Governos, partidos e eleições segundo a opinião pública: o Brasil de 1989 comparado ao de 1964". Dados, vol.32, n 3, 1989.

A democracia nas urnas - o processo partidário eleitoral brasileiro. Rio de Janeiro: Rio Fundo/ IUPERJ, 1991.

Emoções ocultas e estratégias eleitorais. Rio de Janeiro: Objetiva, 2009.

MAINWARING, S. "Políticos, partidos e sistemas eleitorais. O Brasil numa perspectiva comparada". Novos Estudos CEBRAP, n² 29, 1991.

Sistemas partidários em novas democracias: o caso do Brasil. Porto Alegre/Rio de Janeiro: Mercado Aberto/Ed. FGV, 2001.

MENDES, M; VENTURI, G. "Eleição presidencial: o Plano Real na sucessão de Itamar Franco". Opinião Pública, vol.II, $\mathrm{n}^{\circ}$ 2, 1994.

MONDAK, J.J. et al. "The participatory personality: evidence from Latin America". British Journal of Political Science, n 41, 2010.

NICOLAU, J. \& PEIXOTO, V. Uma disputa em três tempos: uma análise das bases municipais das eleições presidenciais de 2006. 31 Encontro Anual da ANPOCS, Caxambu-MG, out. 2007. 
RIBEIRO, E.; CARREIRÃO, Y.; BORBA, J. Sentimentos partidários e atitudes políticas...

PAIVA, D; BRAGA M. S; PIMENTEL, J. "Eleitorado e partidos políticos no Brasil". Opinião Pública, vol.13, n.2, p. 388-408, 2007.

REIS, F. W. "A Razão do Eleitor. Resenha de Esquerda e Direita no Eleitorado Brasileiro, de André Singer (São Paulo, EDUSP, 2000)". Jornal de Resenhas (Folha de S. Paulo), São Paulo, 09 set. 2000.

RENNÓ, L. "Escândalos e voto: as eleições presidenciais brasileiras de 2006". Opinião Pública, vol.13, n², p. 260-282, 2007.

RENNÓ, L.; CABELLO, A. "As bases do Lulismo: a volta do personalismo, realinhamento ideológico ou não alinhamento?" Revista Brasileira de Ciências Sociais, vol.25, p.39-60, 2010.

SAMUELS, D. "As bases do petismo". Opinião Publica, vol.X, n.2, p.221-241, 2004.

. "Evolução do petismo (2002-2008)". Opinião Pública, vol.14, nº 2, p.302-318, 2008.

SINGER, A. Esquerda e direita no eleitorado brasileiro. São Paulo: EDUSP, 2000.

"A segunda alma do partido dos trabalhadores". Novos Estudos CEBRAP, n 88, 2010.

SOARES, G.; e A.; TERRON, S. L. "Dois Lulas: a geografia eleitoral da reeleição (explorando conceitos, métodos e técnicas de análise geoespacial)". Opinião Pública, vol.14, n² 2, p.269. 301, 2008.

TAROUCO, G. "Institucionalização partidária no Brasil (1982-2006)". Revista Brasileira de Ciência Política, n 4, 2010.

TERRON, S. L; SOARES, G. A. D. "As bases eleitorais de Lula e do PT: do distanciamento ao divórcio". Opinião Pública, vol.16, n.2, p.310-337,2010.

VECCHIONE, M.; CAPRARA, G.V. "Personality determinants of political participation: the contributions of traits and self-efficacy beliefs". Personality and Individual Differences, $\mathrm{n}^{\circ} 46$, 2009.

VEIGA, L. "Os partidos brasileiros na perspectiva dos eleitores: mudanças e continuidades na identificação partidária e na avaliação das principais legendas após 2002". Opinião Pública, vol.13, n² 2, p340-365, 2007.

VENTURI, G. "PT 30 Anos: crescimento e mudanças na preferência partidária. Impacto nas eleições de 2010". Revista, Perseu, n 5, 2010.

WATTENBERG, M. "The rise of candidate-centered politics (presidential elections of the 1980's)". Cambridge: Harvard University Press, 1991. 
. "The decline of American political parties, 1952-1996". Cambridge, Massachussets:

Harvard University Press. 1998.

ZUCCO, C. "The President's 'new' constituency: Lula and the pragmatic vote in Brazil's 2006 presidential elections". Journal of Latin American Studies, vol. 40, nº 1, p.29.49, 2008.

\section{TABELAS ANEXAS}

Tabela Anexa 1

Diferença de voto entre candidatos do PT e do PSDB para presidente, segundo sentimentos em relação ao PT e ao PSDB (2002, 2006 e 2010)

\begin{tabular}{|c|c|c|c|c|c|c|c|c|c|}
\hline \multirow{2}{*}{$\begin{array}{c}\text { Eleição } \\
\text { (e survey) }\end{array}$} & \multirow{2}{*}{$\begin{array}{l}\text { Diferença de votos } \\
1^{\circ} \text { turno }\end{array}$} & \multicolumn{7}{|c|}{ Sentimentos em relação ao PT e PSDB * } & \multirow[t]{2}{*}{ Total } \\
\hline & & 1 & 2 & 3 & 4 & 5 & 6 & 7 & \\
\hline ESEB & Lula - Serra(\%) & 86 & 76 & 51 & 16 & 50 & 36 & 66 & 28 \\
\hline 2002 & Total $(\mathrm{N})$ & $(315$ & $(330)$ & $(260)$ & $(752)$ & $(259)$ & $(44)$ & $(70)$ & $(2030)$ \\
\hline ESEB & Lula - Alckmin(\%) & 96 & 92 & 93 & 36 & .53 & 0 & .86 & 41 \\
\hline 2006 & Total $(\mathrm{N})$ & $(115)$ & $(100)$ & $(114)$ & $(354)$ & $(120)$ & $(13)$ & $(28)$ & $(844)$ \\
\hline ESEB & Dilma - Serra (\%) & 86 & 60 & 60 & 10 & .65 & .55 & .82 & 20 \\
\hline 2010 & Total (N) & (295) & (283) & $(196)$ & (724) & (204) & $(62)$ & (98) & (1862) \\
\hline
\end{tabular}

Fontes: ESEB 2002; ESEB 2006; ESEB 2010.

* Sentimentos em relação ao PT e PSDB: 1 = sentimento positivo em relação ao PT e rejeição ao PSDB;

2 = somente sentimento positivo em relação ao PT; 3 = somente rejeição ao PSDB; 4 = situações neutras; 5 = somente rejeição ao PT; 6 = somente sentimento positivo em relação ao PSDB; $7=$ sentimento positivo em relação ao PSDB e rejeição ao PT.

Foram consideradas "situações neutras" aquelas em que o eleitor não manifestou nenhum sentimento em relação aos dois partidos, ou manifestou o mesmo sentimento (positivo ou negativo) em relação aos dois, ou manifestou sentimentos contraditórios (positivos e negativos, simultaneamente, a um mesmo partido). Foram desconsiderados na análise os entrevistados que informaram não ter votado, ou que responderam que não se lembravam em quem haviam votado, ou cuja resposta foi "não sabe" ou "não respondeu" à pergunta sobre o voto no $1^{\circ}$ turno da eleição. As porcentagens foram calculadas sobre o total dos eleitores (em cada categoria de "sentimentos") que disseram ter votado em algum candidato, em branco ou nulo. 
RIBEIRO, E.; CARREIRÃO, Y.; BORBA, J. Sentimentos partidários e atitudes políticas...

Tabela Anexa 2

Correlações (Gamma) entre sentimentos partidários e posicionamento ideológico

\begin{tabular}{|c|c|c|c|}
\hline ESEB & $(\mathbf{N})$ & Gamma & Signif. \\
\hline 2002 & $(1885)$ & 0,273 & 0,000 \\
\hline 2006 & $(581)$ & 0,090 & 0,109 \\
\hline 2010 & $(1104)$ & 0,120 & 0,001 \\
\hline
\end{tabular}

Fonte: ESEBs 2002, 2006 e 2010.

\section{APÊNDICES METODOLÓGICOS}

\section{Apêndice Metodológico 1 - Índice de estatismo}

Foram usadas 4 questões, todas com as seguintes opções de resposta: "1) Concorda muito; 2) Concorda um pouco; 3) Nem concorda nem discorda; 4) Discorda um pouco; 5) Discorda muito". Questões: ESEB94a) "as leis e os impostos do governo impedem as empresas de terem lucros"; ESEB94b) "para que o país cresça, o governo deveria intervir mais na economia"; ESEB94c) "a privatização das empresas estatais foi boa para o país"; ESEB94d) "É preciso dar mais liberdade para as empresas dispensarem os empregados". As respostas foram recodificadas, com os valores das respostas variando de 0 a 4 (com zero correspondendo à resposta que representa "menos estatismo", em cada caso). A análise fatorial demonstrou que as quatro questões podem compor uma única medida de estatismo. Ao construirmos um índice somatório com essas quatro variáveis, temos escala ampla que vai de 0 a 16, com média de 9,85 e desvio de 2.9.

\section{Apêndice Metodológico 2 - Índice de igualitarismo}

Foram usadas 4 questões; as duas primeiras com as seguintes opções de resposta: "1) Concorda muito; 2) Concorda um pouco; 3) Nem concorda nem discorda; 4) Discorda um pouco; 5) Discorda muito". As duas últimas não dispunham da opção 3 "Nem concorda nem discorda". Questões: ESEB63f) "Nós teríamos menos problemas no Brasil, se as pessoas fossem tratadas com mais igualdade"; ESEB63g) "Em um país como o brasil, é obrigação do governo diminuir as diferenças entre os muito ricos e os muito pobres"; ESEB65f) "Tudo o que a sociedade produz deveria ser distribuído entre todos, com a maior igualdade 
possível”; ESEB65g) "Não basta garantir a igualdade de oportunidades. o governo deve também limitar o enriquecimento daqueles que ganham demais". As respostas foram recodificadas, com os valores das respostas às duas primeiras questões variando de 0 a 4 e os valores das outras duas variando de o a 3 (com zero correspondendo à resposta que representa "menos igualitarismo", em cada caso). 0 resultado é um índice com variação de 0 a 14, com média de 11,08 e desvio de 2,69.

Ednaldo Ribeiro - ednaldorib@yahoo.com.br

Julian Borba - borbajulian@yahoo.com.br

Yan Carreirão - yan@cfh.ufsc.br

Recebido para publicação em setembro de 2011. Aprovado para publicação em outubro de 2011. 